\title{
Client satisfaction with English language centre service: insights from a New Zealand national survey
}

\author{
John Walker, Department of Management, Massey University, New Zealand
}

The International Journal of Educational Management, 17/7 [2003] 294-302

(C) MCB UP Limited [ISSN 0951-354X] [DOI 10.1108/09513540310500978]

\begin{abstract}
The TESOL (teaching of English to speakers of other languages) sector in New Zealand is rapidly developing into a major educational service industry. Despite their growing national importance, little is known about the performance of the English language centres (ELCs) that constitute the industry. This study investigated levels of client satisfaction with New Zealand ELC service at a national level. The research took a services management approach, using a multilingual questionnaire covering nine dimensions of ELC service. The findings indicated that, overall, clients registered mere satisfaction with the service provided. Statistical analysis identified significant differences between levels of client satisfaction in terms of client age and nationality and between ELCs of different type and size. While service provider personal attributes were positively rated by respondents, these did not play a major role as predictors of client satisfaction or the willingness to recommend an ELC.
\end{abstract}

Keywords: ELT management; TESOL management; English language; Service delivery; Customer satisfaction; Teaching methods; New Zealand.

\section{Introduction}

Overseas students increasingly represent a major source of income for New Zealand, earning the country some \$NZ1.1 billion (Education New Zealand, 2002) in 2001. English language centres (ELCs) teaching ESOL (English for speakers of other languages) courses for feepaying clients accounted for over one-fifth of these earnings (Education New Zealand, 2002) and their clientele made up 50 per cent of the total 2001 overseas student population. In the same year, the commercial TESOL sector experienced 44 per cent growth and generated some \$NZ245 million in foreign exchange from 26,000 students (Education New Zealand, 2001). Despite this increasing importance to the national economy, little is known about how New Zealand English language centres perform as service operations. The research described here set out to improve our knowledge of ELC operations by examining their performance from a client perspective.

The effectiveness of service operations is viewed in the services literature largely as a function of customer satisfaction with the service process (e.g. Grönroos, 1990; Peterson and Wilson, 1992) since assessment of the quality of a service organisation's output is entirely in the mind of the customer, regardless of any objective efficiency measures or "expert" opinion (Bowen and Ford, 2002). Measures of customer perceptions of the quality of the service process outputs thus represent good practice in terms of service performance measurement 
(Voss et al., 1990). Furthermore, service organisations like ELCs benefit when satisfied clients make word-of-mouth recommendations to friends and acquaintances, thereby helping to boost future client numbers (Walker, 2001). The client perspective on ELC service is therefore of interest as a key performance indicator. With this in mind, a research study was devised to investigate levels of client satisfaction with the service performance of New Zealand English language centres.

\section{Methodology}

Client and staff focus groups conducted at ELCs throughout New Zealand identified key issues surrounding ELC service and particularly client satisfaction "drivers" (Bowen and Ford, 2002). The findings, combined with insights from the services theory, were integrated into a client satisfaction questionnaire which used a disconfirmation of expectations format (Cardozo, 1965; Churchill and Suprenant, 1982; Danaher and Haddrell, 1996; Oliver, 1980; Szymanski and Henard, 2001) based on a five-point Likert scale with a do-not-know option. Respondents were asked to circle the number that indicated their level of satisfaction with the particular aspect of the service.

Table I: ELC client satisfaction rating scale

\begin{tabular}{clll}
\hline RATING & SCALE DESIGNATION & INDICATION & INTERPRETATION \\
\hline $\mathbf{1}$ & far worse than l expected & strong dissatisfaction & DISAPPOINTMENT \\
$\mathbf{2}$ & worse than l expected & dissatisfaction & DISAPPOINTMENT \\
$\mathbf{3}$ & about what l expected & satisfaction & MERE SATISFACTION \\
$\mathbf{4}$ & better than l expected & strong satisfaction & DELIGHT \\
$\mathbf{5}$ & far better than l expected & very strong satisfaction & DELIGHT \\
\hline
\end{tabular}

Table I displays the ratings with their associated designations, indications and broad interpretations. While a rating of three indicates satisfaction with the service, this has been referred to as mere satisfaction (Patterson, 1993). For the purposes of this study, means in the range 2.6-3.4 were taken to indicate mere satisfaction. In terms of services best practice, mere satisfaction on the part of customers is not enough to produce the sort of word-of-mouth client recommendation which helps generate future business for ELCs, since "marginally satisfied customers are at risk of being lured away by a competitor's offering” (Lovelock et al., 1998, pp. 116-17). Instead, clients should be expressing strong/very strong satisfaction or delight. Ideally, therefore, responses should be concentrated in the better than expected or far better than expected categories.

A common weakness of internally developed ELC feedback instruments is their utilisation of English as the survey language, since inaccurate comprehension by non-native speaker respondents with low English proficiency levels can limit the usefulness of the data and invite criticism of lack of content validity. The questionnaire was therefore translated into the languages of the major ELC client groups in New Zealand at the time the study was initiated; namely, Japanese, Mandarin, Korean and German. The four translated versions were then combined with the English version to produce a multilingual format. Pre-testing of the questionnaire with peer groups of ELC clients led to further refinement. The final version consisted of 74 items in nine service dimensions (below), plus a recommendation question and client personal data questions: 
1. the teachers;

2. the English lessons;

3. the service procedures;

4. communication;

5. the administrative staff;

6. the homestay;

7. the facilities;

8. the activities programme; and

9. general aspects of the service.

Lists of ELCs on the New Zealand TESOL marketing and industry association Web sites were taken as a sampling frame. At the time of the survey, these lists contained details of 21 tertiary institutions and 55 private institutions in New Zealand offering ESOL courses. All 76 ELCs were invited to participate in the research and 30 ELCs or some 40 per cent of the population accepted the invitation. A total of eight ELCs (27 per cent) were tertiary-owned and 22 (73 per cent) were privately owned, these proportions almost exactly mirroring those in the general population. The geographical distribution of the participating ELCs was also a good reflection of the national spread.

Feedback data from ELC clients is sometimes criticised as potentially inaccurate since, anecdotally, cultural constraints may prevent respondents from writing what they really think about the service. Common barriers are reluctance to cause offence and fear of being associated with critical comments, especially as surveys may be supervised and completed questionnaires collated by the very staff whose performance clients are assessing. To forestall such problems, all surveys were personally conducted by the researcher. Participants were given a multilingual letter assuring them of the confidentiality of the process and the data and emphasising that no staff from their ELC would see their responses. By arrangement with ELC management, no staff members were present during questionnaire completion. It was hoped that these measures would further reinforce the validity of the data.

The survey was conducted over a three-month period. From a total client population of 3,858, a sample of 1,835 was taken. Of the sample, 7 per cent or 108 clients, declined to participate, 19 clients were excluded for various reasons and 24 questionnaires were incomplete. A total of 1,684 usable responses was therefore obtained for a response rate of 92 per cent.

Once the raw data had been entered, it was examined for skewness and reliability and the criteria for multiple regression were applied. Scales used to measure satisfaction have been observed to suffer from asymmetry, the findings commonly being skewed towards the top of the scale (Devlin et al., 1993; Rust et al., 1994). The use of the disconfirmation scale was recommended by Danaher and Haddrell (1996) as having the ability to correct this error. An examination of the data appeared to support Danaher's and Haddrell's endorsement, since no overall skewness was observed. Cronbach's alpha (Cronbach, 1951) for the complete scale was 0.9792, indicating good internal consistency. An examination of dimension intercorrelations revealed moderate to large, positive correlations $(p<0.01)$. All assumptions for regression analysis were satisfied. 


\section{Findings and discussion}

\section{Selected respondent classification data}

- 52 per cent of respondents were female and 48 per cent male;

- 94 per cent of respondents were from Asia, 4 per cent from Europe and Russia, 1 per cent from South America and 1 per cent from miscellaneous regions; and

- 22.5 per cent were aged 14-19 years; 62 per cent were aged 20-29; 9.8 per cent were aged 30-39; and 5.7 per cent were aged $40+$ years.

\section{Overview of client satisfaction}

An overview of the dimension rankings, means and response category percentages is displayed in Table II.

Table II: ELC client satisfaction dimension means, response category summary

\begin{tabular}{llllll}
\hline RANK & Dimension & M & $\begin{array}{l}\text { Per cent worse } \\
\text { /far worse } \\
\text { than expected* }\end{array}$ & $\begin{array}{l}\text { Per cent about } \\
\text { what expected* }\end{array}$ & $\begin{array}{l}\text { Per cent better } \\
\text { /far better } \\
\text { than expected* }\end{array}$ \\
\hline $\mathbf{1}$ & Teachers & 3.60 & 12 & 35 & 53 \\
$\mathbf{2}$ & Admin Staff & 3.40 & 16 & 39 & 45 \\
$\mathbf{3}$ & Homestay & 3.26 & 27 & 30 & 43 \\
$\mathbf{4}$ & Service Procedures & 3.04 & 27 & 44 & 29 \\
$\mathbf{5}$ & English Lessons & 3.03 & 28 & 43 & 29 \\
$\mathbf{6}$ & General & 2.97 & 31 & 41 & 28 \\
$\mathbf{7}$ & Communication & 2.93 & 28.7 & 48.8 & 22.5 \\
$\mathbf{8}$ & Activities Programme & 2.85 & 32 & 39 & 29 \\
$\mathbf{9}$ & Facilities & 2.67 & 42.5 & 36.6 & 20.9 \\
\hline
\end{tabular}

* Percentages subjected to rounding.

Respondents expressed strong satisfaction with the teachers. Ratings for the admin staff bordered on strong satisfaction. Respondents were satisfied with the homestay, English lessons, service procedures, general aspects of the service, communication and the activities programme. Ratings for facilities bordered on dissatisfaction. The overall picture therefore indicates mere satisfaction with the bulk of the service dimensions. In the following sections, the findings from selected dimensions are examined in more detail.

\section{English teachers}

The data (Table III) indicates overall strong satisfaction with most aspects of the teacher's performance. However, an examination of the rankings shows that the top rated items tend to be associated with human or personal attributes such as friendliness, patience or helpfulness. The lower rated items, on the other hand, tend to be the sorts of acquired skills or abilities expected of effective teachers, such as the ability to make lessons interesting, subject 
knowledge or the ability to explain. The fact that friendliness ranks top but teaching skills rank bottom is particularly noteworthy. These findings show respondents perceived a strong ESOL teacher affective base but weak knowledge and experience bases (Richard-Amato, 1996).

Table III: ELC client satisfaction with teachers: Item means ranked

\begin{tabular}{llll}
\hline RANK & VARIABLE & M & SD \\
\hline $\mathbf{1}$ & Friendliness & 4.04 & 0.89 \\
$\mathbf{2}$ & Willingness to help in class & 3.85 & 0.90 \\
$\mathbf{3}$ & Ability to be patient & 3.78 & 0.93 \\
$\mathbf{4}$ & Communication skills & 3.69 & 0.88 \\
$\mathbf{5 =}$ & Professionalism & 3.51 & 0.92 \\
$\mathbf{5 =}$ & Flexibility & 3.51 & 0.99 \\
$\mathbf{5 =}$ & Overall quality & 3.51 & 0.87 \\
$\mathbf{8 =}$ & Lesson preparation & 3.48 & 0.94 \\
$\mathbf{8 =}$ & Ability to give clear explanations & 3.48 & 0.90 \\
$\mathbf{1 0}$ & Knowledge of the subject & 3.41 & 0.92 \\
$\mathbf{1 1}$ & Availability to help out of class & 3.38 & 1.07 \\
$\mathbf{1 2}$ & Ability to teach interesting lessons & 3.35 & 0.98 \\
$\mathbf{1 3}$ & Teaching skills & 3.33 & 0.92 \\
\hline
\end{tabular}

\section{English lessons}

The data (Table IV) indicates mere satisfaction with English lessons, with the bottom-ranked item bordering dissatisfaction. The item ranking demonstrates that respondents gave higher ratings to items which would tend to be more under the control of the teacher, such as the teaching methods or the interest level. On the other hand, items that tend to be more under management control, such as the class size or the mix of nationalities, attracted lower ratings. The issue of management control versus teacher control of aspects of the English lessons was raised in the staff focus groups (Walker, 2000) and these findings provide an interesting comment from the client perspective.

\section{Admin Staff}

The findings (Table V) represent overall satisfaction with the performance of the admin staff with five out of seven items in the mere satisfaction range. The differences in means are not large but a similar trend to that for the teachers is apparent. The two top-rated items are personal attributes, while the bottom two are the sorts of skills effective front-line service staff would be expected to possess. It is striking that friendliness and ability to give the right information are ranked top and bottom, respectively. Respondents therefore rated admin staff more strongly on their personal attributes than on the basic skills they need for the job. 
Table IV: ELC client satisfaction with English lessons: Item means ranked

\begin{tabular}{llll}
\hline RANK & VARIABLE & M & SD \\
\hline $\mathbf{1}$ & Teaching methods & 3.21 & 0.92 \\
$\mathbf{2}$ & Interest level & 3.17 & 0.91 \\
$\mathbf{3}$ & Overall quality & 3.09 & 0.84 \\
$\mathbf{4}$ & Effectiveness & 3.08 & 0.92 \\
$\mathbf{5}$ & Content & 3.06 & 0.86 \\
$\mathbf{6}$ & Quality of learning materials & 2.97 & 0.96 \\
$\mathbf{7}$ & Class size & 2.92 & 1.08 \\
$\mathbf{8}$ & Relevance & 2.84 & 0.98 \\
$\mathbf{9}$ & Mix of nationalities in class & 2.61 & 1.20 \\
\hline
\end{tabular}

Table V: ELC client satisfaction with admin staff: Item means ranked

\begin{tabular}{llll}
\hline RANK & VARIABLE & M & SD \\
\hline $\mathbf{1}$ & Friendliness & 3.66 & 0.97 \\
$\mathbf{2}$ & Willingness to help & 3.47 & 0.97 \\
$\mathbf{3}$ & Availability to help & 3.35 & 0.97 \\
$\mathbf{4}$ & Communication skills & 3.33 & 0.89 \\
$\mathbf{5}$ & Overall quality & 3.32 & 0.94 \\
$\mathbf{6}$ & Ability to understand client needs & 3.24 & 1.00 \\
$\mathbf{7}$ & Ability to give right information & 3.23 & 0.99 \\
\hline
\end{tabular}

\section{Homestay}

The homestay data (Table VI) reveals overall mere satisfaction, with friendliness the only item receiving a strong satisfaction rating. As with the teachers and the admin staff, respondents were most satisfied with human aspects of the service. Organisational issues such as match with the homestay requested and amount of time hosts spend with client attracted negative comments in the focus groups and the relatively modest rankings for these items may reflect these concerns. 


\section{Facilities}

Despite services' intangible character, tangible dimensions such as facilities and equipment play a key role in the service provision (Bitner, 1992; Hightower et al., 2002; Parasuraman et al., 1988; Shamdasani and Balakrishnan, 2000). The low mean rating $\left(x^{-}=2.67\right)$ for facilities indicated at best borderline client dissatisfaction with this dimension, with four items clearly rated worse than expected (Table VII). Some items recorded the highest worse than expected scores in the entire survey. For instance, 57 per cent, 54 per cent and 51 per cent of respondents, respectively, found the audio equipment, computers and video equipment worse or far worse than expected. Overall, respondents were barely satisfied with the facilities and equipment provided by their ELCs.

Table VI: ELC client satisfaction with homestay: Item means ranked

\begin{tabular}{llll}
\hline RANK & VARIABLE & M & SD \\
\hline $\mathbf{1}$ & Friendliness of hosts & 3.61 & 1.17 \\
$\mathbf{2}$ & Atmosphere & 3.35 & 1.21 \\
$\mathbf{3}$ & Physical comfort level & 3.32 & 1.18 \\
$\mathbf{4}$ & Overall quality & 3.31 & 1.18 \\
$\mathbf{5}$ & Host willingness to help with English & 3.22 & 1.24 \\
$\mathbf{6}$ & Opportunity to speak English & 3.16 & 1.21 \\
$\mathbf{7 =}$ & Match with homestay requested & 3.10 & 1.15 \\
$\mathbf{7 =}$ & Quality of the food & 3.10 & 1.24 \\
$\mathbf{9}$ & Amount of time hosts spend with client & 3.02 & 1.25 \\
\hline
\end{tabular}

Table VII: ELC client satisfaction with facilities: Item means ranked

\begin{tabular}{llll}
\hline RANK & VARIABLE & M & SD \\
\hline $\mathbf{1 =}$ & Classrooms & 3.06 & 0.91 \\
$\mathbf{1 =}$ & Toilets/bathrooms & 3.06 & 0.96 \\
$\mathbf{3}=$ & Student lounge/cafeteria & 2.70 & 1.02 \\
$\mathbf{3}=$ & Overall quality & 2.70 & 0.91 \\
$\mathbf{5}$ & Library & 2.69 & 1.24 \\
$\mathbf{6}$ & Self-access unit & 2.54 & 1.08 \\
$\mathbf{7}$ & Computers & 2.48 & 1.15 \\
$\mathbf{8}$ & Video equipment & 2.45 & 1.02 \\
$\mathbf{9}$ & Audio equipment & 2.30 & 1.03 \\
\hline
\end{tabular}




\section{General Items}

The general findings (Table VIII) represent overall satisfaction, with eight out of nine items in the mere satisfaction range. Rate of improvement and value for money received the weakest ratings. Over one-third of respondents perceived their progress with English to be worse or far worse than they expected. Value for money ranked 73rd out of the 74 individual satisfaction items. Over 50 per cent of respondents found this to be worse or far worse than they expected.

Table VIII: ELC client satisfaction with general items: Item means ranked

\begin{tabular}{llll}
\hline RANK & VARIABLE & M & SD \\
\hline $\mathbf{1}$ & Atmosphere & 3.13 & 0.95 \\
$\mathbf{2}$ & Opportunity to use English & 3.11 & 1.03 \\
$\mathbf{3}$ & Student national mix & 3.10 & 1.17 \\
$\mathbf{4}$ & Encouragement to achieve goals & 3.01 & 0.99 \\
$\mathbf{5}$ & Overall organisation & 2.99 & 0.85 \\
$\mathbf{6}$ & Physical comfort level & 2.96 & 0.92 \\
$\mathbf{7}$ & Overall quality of ELC service & 2.94 & 0.87 \\
$\mathbf{8}$ & Rate of improvement in English & 2.78 & 0.98 \\
$\mathbf{9}$ & Value for money of programme & 2.44 & 1.03 \\
\hline
\end{tabular}

\section{Recommendation of the ELC}

Since satisfied clients are potential marketers for service organisations like ELCs (Dawes et al., 1992; Hall, 1996; Soutar et al., 1994), a measure of client willingness to recommend is a key indicator for ELC managers. The survey therefore included the question: Would you recommend this English language centre to your friends? Across individual ELCs, there was considerable variation in percentages of clients who would recommend, ranging from 84 per cent to 22 per cent. Overall, 56 per cent of respondents said they would recommend, 34 per cent said they would not and 10 per cent gave no response. Although comparable recommendation data at this level is not widely available, an Australian survey of ELC clients (ELICOS, 1997) using a similar question but without a no response option returned a recommendation rate of 62 per cent. If only valid responses from this present survey were taken into account, the response rate would be identical to that of the Australian survey. Interpretation of such findings is difficult without a range of data from similar studies. Expectation of 100 per cent client willingness to recommend is unrealistic. While some ELC managers might be satisfied with the recommendation rate reported here, others might prefer to see a more positive client response to their service provision. 


\section{Group differences}

In order to identify statistically significant group differences, respondent data was examined in terms of gender, age, nationality and length of time in the ELC; ELCs were examined in terms of type and size. A $t$-test comparing male and female data revealed only a few significant differences of a very small magnitude $\left(p<0.01\right.$ and $\left.p<0.05, \eta^{2}<0.01\right)$, the only noticeable pattern being that in every case mean female ratings of ELC service were lower than mean male ratings. This finding indicated that male and female clients barely differed in their levels of satisfaction with ELC service.

Respondents indicated their age group according to the categories 14-19, 20-29, 30-39 and 40 -plus. Comparison of the group data for the nine dimensions plus the recommendation data showed that the 40-plus group was most satisfied with ELC service and most likely to recommend, while the 20-29 group was least satisfied and least likely to recommend (Table IX and Figure 1).

Table IX: Client age groups ranked on level of satisfaction with ELC service

\begin{tabular}{ll}
\hline LEVEL OF SATISFAction & AgE GROUP \\
\hline MOST SATISFIED & 40-plus years \\
& $14-19$ years \\
LEAST SATISFIED & $30-39$ years \\
& $20-29$ years \\
\hline
\end{tabular}

Figure 1: Client age group differences in willingness to recommend an ELC

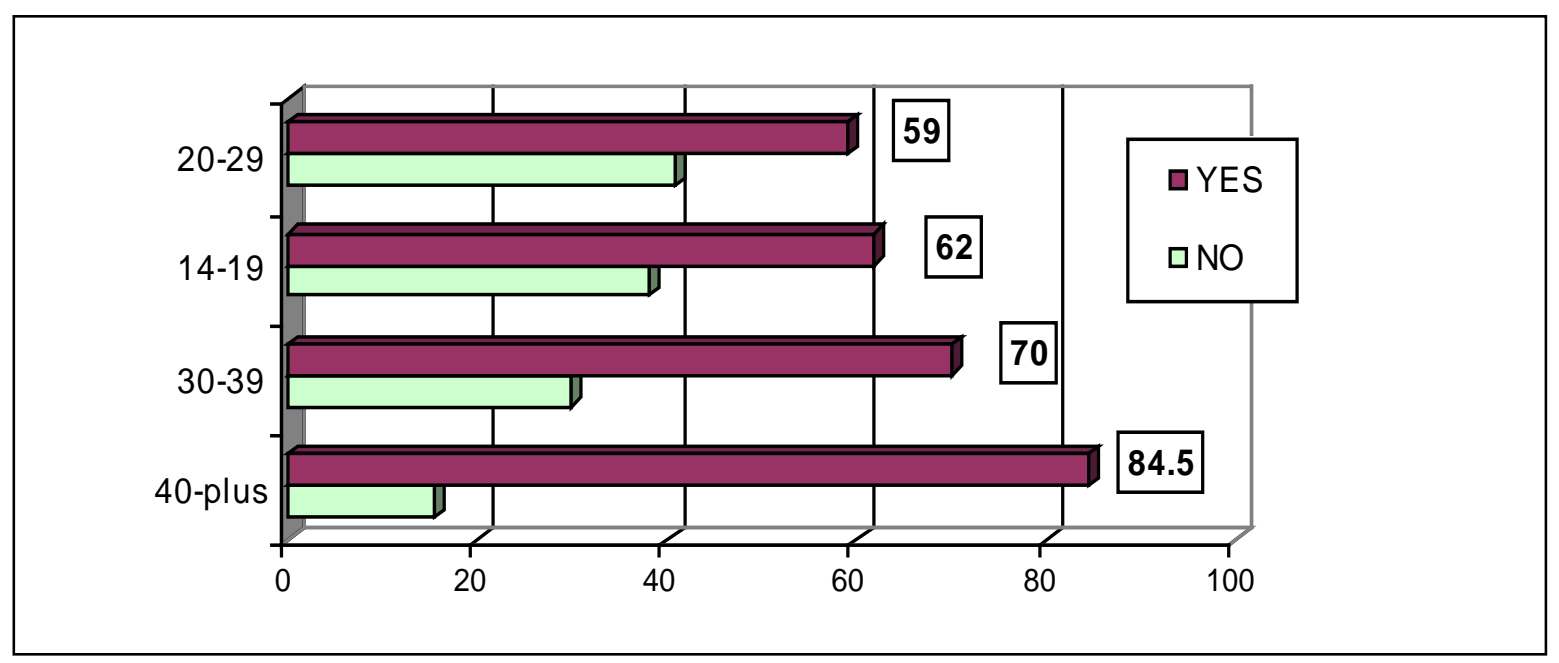

Analysis of variance (ANOVA) revealed the differences between the age groups were significant for the recommendation and six dimensions $(p<0.01)$, and for a further dimension $(p<0.05)$. No significance was established for the dimensions homestay and activities. The 
effect size for the teachers dimension bordered on the moderate $\left(\eta^{2}=0.049\right)$, but all other effect sizes were small $\left(\eta^{2}=0.01-0.03\right)$ (Cohen, 1988). The findings therefore established modest but significant differences in client satisfaction levels relative to age.

Table X: Client national groups ranked on level of satisfaction with ELC service

\begin{tabular}{cc}
\hline LEVEL OF SATISFACTION & NATIONAL GROUP \\
\hline MOST SATISFIED & Switzerland \\
& Thailand \\
& Other \\
& Taiwan \\
& Japan \\
LEAST SATISFIED & P.R. China \\
\hline
\end{tabular}

Figure 2

Client national differences in willingness to recommend an ELC

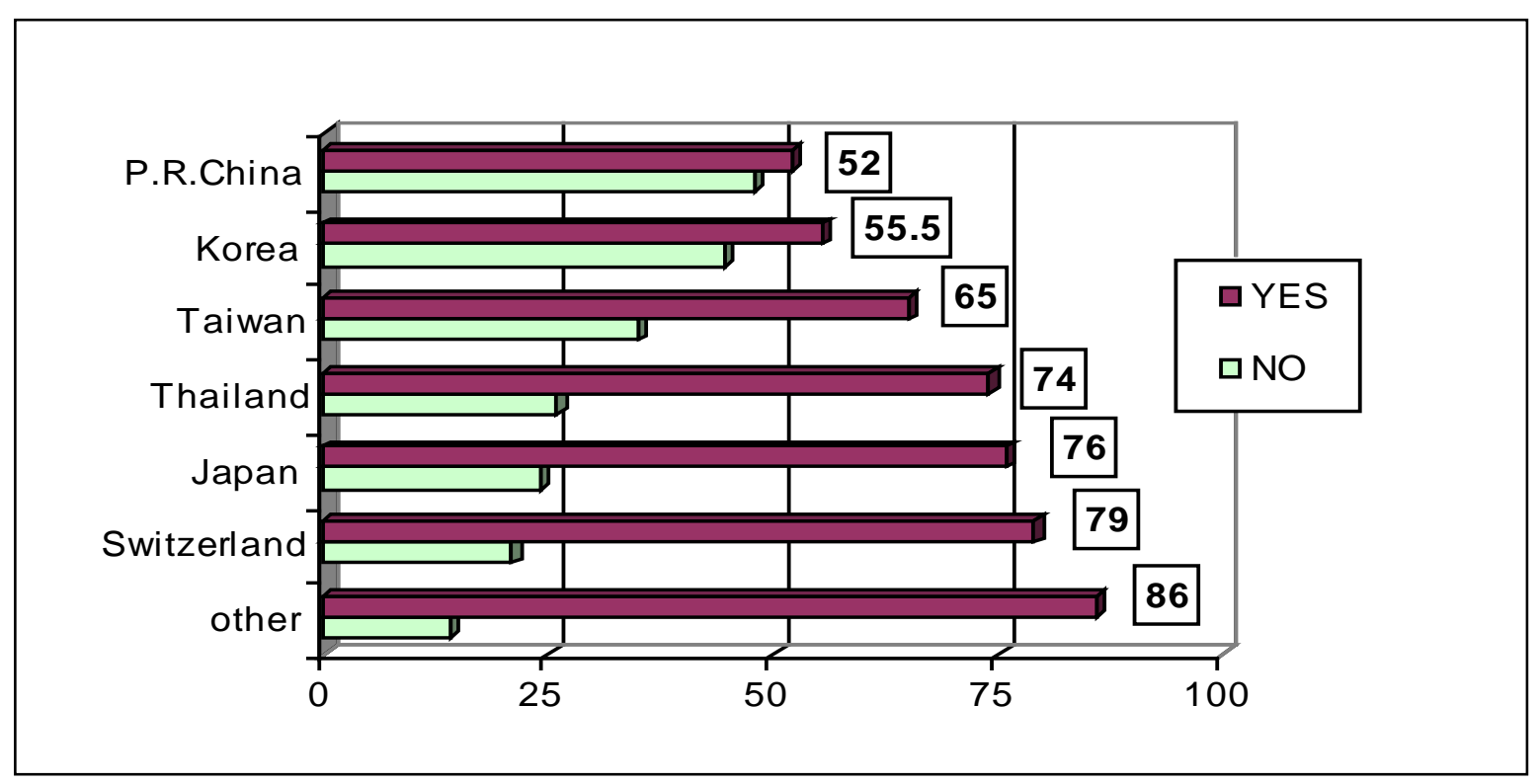

In order to ascertain whether client nationality influenced satisfaction levels, the data from the nine dimensions and the recommendation was examined in terms of the six major national groups in the survey and a seventh group, other (comprising the other 35 nationalities). Analysis showed that Swiss clients were most satisfied and Korean clients least satisfied. Other clients were most willing to recommend, while clients from the People's Republic of China (PR China) were least likely to recommend (Table X and Figure 2). The ANOVA revealed that variation between the groups was significant $(p<0.01)$ for all nine dimensions and the recommendation. While six of the dimensions displayed small effect sizes $\left(\eta^{2}=0.02\right.$ $0.05)$, two, namely teachers $\left(\eta^{2}=0.06\right)$ and activities $\left(\eta^{2}=0.06\right)$, as well as the recommendation $\left(\eta^{2}=0.06\right)$, bordered on a moderate effect size (Cohen, 1988). These findings indicate significant differences in client satisfaction levels relative to client nationality. 
Table XI

\begin{tabular}{ll}
\hline Group & No of Weeks in ELC \\
\hline $\mathbf{1}$ & 1-2 weeks \\
$\mathbf{2}$ & 3-4 weeks \\
$\mathbf{3}$ & $5-8$ weeks \\
$\mathbf{4}$ & $9-12$ weeks \\
$\mathbf{5}$ & 13-26 weeks \\
$\mathbf{6}$ & $27+$ weeks \\
\hline
\end{tabular}

Anecdotally, clients might change their perceptions of ELC service depending on the length of time they remain in an ELC. In order to test this notion, the data was split into six groups (see Table XI) and subjected to ANOVA. Included was the dimension and recommendation data as before, plus five items from the general dimension which might be especially susceptible to change over time, such as physical comfort level and rate of improvement in English proficiency. The findings showed that client satisfaction ratings weakened slightly as time went on, then strengthened towards the end of the period, indicating a small but gradual waning, then waxing of satisfaction. However, only four of the 15 variables demonstrated significance $(p<0.01$ and $p<0.05)$ and the effect size was small $\left(\eta^{2}=0.01\right)$ (Cohen, 1988). There was therefore little evidence for substantial or statistically significant variation in client satisfaction over the period of client sojourn at the ELC.

A $t$-test was used to compare tertiary and private sector ELC dimension and recommendation data and the nine general dimension items. Findings showed that tertiary ELCs scored marginally higher than private ELCs in six dimensions, marginally lower in one and identically in two. A similar pattern could be seen in the general items as well as in the recommendation. With the exception of four dimensions and two of the general items, significance was demonstrated at the $p=0.01$ or $p=0.05$ level. Some 66 per cent of tertiary ELC clients were willing to recommend their ELCs compared to 60 per cent of private ELC clients $(p<0.05)$. Among the significant dimensions and items, however, the effect size was small $\left(\eta^{2}<0.01\right)$, with the exception of the facilities dimension $\left(\eta^{2}=0.07\right)$ and the general item physical comfort level $\left(\eta^{2}=0.04\right)$ (Cohen, 1988). There was some support, therefore, for significant but modest variation in client satisfaction according to ELC type, tertiary ELCs producing the more satisfied group of clients, particularly in terms of tangible aspects of the service.

Table XII

\begin{tabular}{lll} 
ELC size & Client numbers & ELC numbers \\
\hline Small & Up to 99 & 14 \\
Medium & 100 to 199 & 9 \\
Large & 200 plus & 7
\end{tabular}

Client satisfaction dimension data and general item data for three ELC size categories (see Table XII) was compared using the same data sets as for ELC type. The ANOVA showed small ELCs enjoyed the highest levels of satisfaction in seven out of the nine dimensions and in all general

items. Large ELCs were marginally ahead of the medium-sized ELCs. Some 70 per cent of clients in small ELCs said they would recommend their ELCs but only 57 per cent in medium and large ELCs would recommend. With the exception of homestay, all dimensions, items and the recommendation were significant $(p<0.01)$ with effect sizes in the small to moderate range $\left(\eta^{2}=0.01-0.05\right)$ (Cohen, 1988). The data indicates, therefore, modest but significant differences in client satisfaction levels between ELCs of different size, ELCs with under 100 clients having the most satisfied clientele. 


\section{Predictors of client satisfaction}

When client satisfaction and client recommendation data were compared, a strong, positive correlation was evident $(r=0.861, p=0.00)$. This suggests that a willingness to recommend an ELC is closely linked to client levels of satisfaction and underlines the status of the recommendation as a key performance indicator. In order to identify predictors of satisfaction, therefore, both the satisfaction and recommendation data were subjected to regression analysis and findings for the two sets of regressions compared. Client ratings for individual items in the nine service dimensions were designated as dependent variables and the overall satisfaction scores and recommendation data designated as independent variables. From the regression data, primary and secondary predictors of overall client satisfaction $(p<0.01)$ and willingness to recommend $(p<0.01$ and $p<0.05)$ were identified (Table XIII) The comparison of the two sets of predictors revealed correspondences across eight of the nine dimensions (Table XIII). The exception was the service procedures dimension where there were none. Those corresponding predictors (Table XIII, italics) can be regarded as common predictors of overall client satisfaction $(p<0.01)$.

The human dimension is traditionally regarded as vital to the service process (Butcher et al., 2001; Lovelock et al., 1998; Normann, 1984). Human attributes such as friendliness and helpfulness on the part of service providers are regarded as integral to service orientation, which has enjoyed some prominence in the services management literature (e.g. Baydoun et al., 2001; Burchell et al., 1999; Hogan, 1992, cited in Cran, 1994; McBride et al., 1997). A positive service orientation has been seen to be a key component of an effective service operation. The dimension descriptive data displayed in Tables III to VIII showed that respondents rated the ELC service very positively on such aspects of the service. For instance, friendliness was ranked top in the teacher, admin staff and homestay dimensions. However, regression analysis identified no personal attributes among the 18 primary predictors of client satisfaction and the willingness to recommend. Among the 18 secondary predictors there were only two, admin staff friendliness and encouragement to achieve goals. As Table XIII makes clear, the predictors of satisfaction and recommendation, rather, tended to consist of professional skills, organisational issues or management-related aspects associated with effective service. For instance, although teachers were perceived to be friendly, it was not their friendliness but their teaching skills that were most likely to lead to a client recommendation.

While elements of service orientation were highly rated by the respondents in this study therefore, they did not actually play a prominent role in satisfying respondents or in prompting them to recommend an ELC. This finding furnishes a practical reminder of what Schneider and Bowen (1995) have called the human resources trap. They cautioned against service managers' over-reliance on service provider attitudes and behaviours to produce client satisfaction at the expense of other service dimensions such as facilities and manager support, a strategy which might make for a friendly service but not necessarily an effective one. 
Table XIII: Comparison of client satisfaction predictors and recommendation predictors

\begin{tabular}{|c|c|c|}
\hline DIMENSION & $\begin{array}{l}\text { PREDICTORS OF CLIENT SATISFACTION } \\
\text { WITH ELC SERVICE* }\end{array}$ & $\begin{array}{l}\text { PREDICTORS OF WILLINGNESS } \\
\text { TO RECOMMEND AN ELC* }\end{array}$ \\
\hline \multirow[t]{2}{*}{ Teachers } & 1. Availability to help out of class & 1. Teaching skills \\
\hline & 2. Teaching skills & 2. Teacher communication skills \\
\hline \multirow[t]{2}{*}{ Lessons } & 1. Mix of nationalities in class & 1. Effectiveness of lessons \\
\hline & 2. Methods used to teach you & 2. Mix of nationalities in class \\
\hline \multirow{2}{*}{$\begin{array}{l}\text { Service } \\
\text { Procedures }\end{array}$} & 1. Enquiries procedure & 1. Student feedback procedure \\
\hline & 2. Placement procedure & 2. Complaints procedure \\
\hline Communication & $\begin{array}{l}\text { 1. Accuracy of information in } \\
\text { publicity materials }\end{array}$ & $\begin{array}{l}\text { 1. Accuracy of information in } \\
\text { publicity materials }\end{array}$ \\
\hline \multirow[t]{2}{*}{ Admin Staff } & 1. Ability to give information & 1. Ability to give information \\
\hline & 2. Communication skills & 2. Friendliness \\
\hline \multirow[t]{2}{*}{ Homestay } & $\begin{array}{l}\text { 1. Opportunity to speak English } \\
\text { with host family }\end{array}$ & $\begin{array}{l}\text { 1. Opportunity to speak English } \\
\text { with host family }\end{array}$ \\
\hline & $\begin{array}{l}\text { 2. Match between homestay } \\
\text { requested and allocated }\end{array}$ & $\begin{array}{l}\text { 2. Match between homestay } \\
\text { requested and allocated }\end{array}$ \\
\hline \multirow[t]{2}{*}{ Facilities } & 1. Classrooms & 1. Classrooms \\
\hline & 2. Self-access unit & 2. Self-access unit \\
\hline \multirow{2}{*}{$\begin{array}{l}\text { Activities } \\
\text { programme }\end{array}$} & 1. Organisation & 1. Value for money \\
\hline & 2. Information about & 2. Organisation \\
\hline \multirow[t]{2}{*}{ General } & 1. Overall organisation of ELC & 1. Value for money of programme \\
\hline & 2. Encouragement to achieve goals & 2. Encouragement to achieve goals \\
\hline
\end{tabular}

* 1 = primary predictor; 2 = secondary predictor 


\section{Conclusions and implications}

Against a background of a rapidly growing New Zealand TESOL sector, this study has thrown some light on client satisfaction with the service provided by New Zealand English language centres. The findings show that clients of New Zealand ELCs are, overall, satisfied with the service they received; clients were most satisfied with service staff and least satisfied with facilities. However, this level of satisfaction can be characterised as mere satisfaction rather than the strong satisfaction that is likely to generate word-of-mouth recommendation. At under 60 per cent, the willingness-to-recommend rate appears to reflect this level of satisfaction. Taken together, these findings suggest that some New Zealand English language centres may need to do more to raise client satisfaction levels, thereby increasing the potential for the spread of positive word-of-mouth about their institutions.

As a general pattern across dimensions, human aspects of the service received better ratings than management, organisational and professional aspects. Nevertheless, human aspects were not well-represented among the predictors of client satisfaction or client willingness to recommend an ELC. The strongest predictors were, rather, those items associated with professional, organisational and managerial effectiveness. This implies that while the human dimension remains an integral part of the service provision, ELC managers should not fall into the human resources trap by overestimating its role in creating and maintaining client satisfaction: ELC clients appear to want much more than just friendly staff. In order to promote client satisfaction, ELC managers would therefore be advised to focus on traditional management functions such as planning and organisation as well as on ensuring that teachers are qualified and competent and that admin staff have the requisite skills to provide effective service.

The findings that client age group and client nationality are linked to levels of satisfaction, while gender and length of client stay are not, may simply confirm empirically what some ELC managers already suspect. The fact that some client groups are less satisfied than others might have as much to do with disappointed expectations as with actual service quality. If so, ELC managers need to be proactive in targeting those groups in order to manage their expectations of the service, with a view to raising their levels of satisfaction. Tertiary ELCs are likely to be better endowed than private ELCs in terms of staff and facilities, which may account for the marginally better satisfaction levels. Where size is concerned, it appears that to ELC clients “small is beautiful”.

Rapid growth of the type witnessed in the TESOL sector in New Zealand in recent years has the potential to place strains on infrastructure and service delivery systems. It is not clear to what extent the findings described here are a reflection of such growth. Further research of this kind is therefore needed, both in New Zealand and overseas, to enable us to better understand the nature of ELC client satisfaction, with a view to enhancing the effectiveness of ELC operations and thus the quality of ELC performance from a client perspective. 


\section{References}

Baydoun, R., Dale, R., Emperado, T. (2001), "Measuring customer service orientation: an examination of the validity of the customer service profile", Services Marketing Quarterly, Vol. 22 No.3, pp.1-19.

Bitner, M.J. (1992), "Servicescapes: The impact of physical surroundings on customers and employees", Journal of Marketing, Vol. 56 No.April, pp.57-71.

Bowen, J., Ford, R.C. (2002), "Managing service organizations: does having 'thing' make a difference?", Journal of Management, Vol. 28 No.3, pp.447-69.

Burchell, N., Hodges, D., Rainsbury, L. (1999), "Graduate pay dirt", New Zealand Management, Vol. 46 No.10, pp.43-4.

Butcher, K., Sparks, B., O’Callaghan, F. (2001), "Evaluative and relational influences on service loyalty", International Journal of Service Industry Management, Vol. 12 No.4, pp.310-27.

Cardozo, R.N. (1965), "An experimental study of consumer effort, expectations and satisfaction", Journal of Marketing Research, Vol. 2 No.3, pp.244-9.

Churchill, G.A., Suprenant, C. (1982), "An investigation into the determinants of customer satisfaction", Journal of Marketing Research, Vol. 19 No.4, pp.491-504.

Cohen, J. (1988), Statistical Power Analysis for the Behavioral Sciences, Erlbaum, Hillsdale, NJ.

Cran, D.J. (1994), "Towards validation of the service orientation construct", Service Industries Journal, Vol. 14 No.1, pp.34-44.

Cronbach, L.J. (1951), "Coefficient alpha and the internal structure of tests", Psychometrika, Vol. 16 No.3, pp.297-334.

Danaher, P.J., Haddrell, V. (1996), "A comparison of question scales used for measuring customer satisfaction", International Journal of Service Industry Management, Vol. 7 No.4, pp.4-26.

Devlin, S.J., Dong, H.K., Brown, M. (1993), "Selecting a scale for measuring quality", Marketing Research, Vol. 5 No.3, pp.12-17. 
Education New Zealand (2001), New Zealand Full Fee Student Statistics 2000, Education New Zealand, Wellington.

Education New Zealand (2002), New Zealand Full Fee Student Statistics 2001, Education New Zealand, Wellington.

ELICOS (1997), A Study of the ELICOS Industry in Australia 1996, ELICOS Assocation, Sydney.

Grönroos, C. (1990), Services Management and Marketing: Managing the Moments of Truth in Service Competition, Lexington Books, Lexington, MA.

Hall, K. (1996), An Investigation into the Japanese Export Education Market in New Zealand, New Zealand Education International Ltd, Wellington.

Hightower, R., Brady, M.K., Baker, T.L. (2002), "Investigating the role of physical environment in hedonic service consumption: an exploratory study of sporting events", Journal of Business Research, Vol. 55 No.9, pp.697-708.

Lovelock, C.H., Patterson, P.G., Walker, R.H. (1998), Services Marketing: Australia and New Zealand, Prentice-Hall, Sydney.

McBride, A., Mendoza, I., Carraher, S. (1997), "Development of a biodata index to measure service-orientation", Psychological Reports, Vol. 81 pp.1395-407.

Normann, R.N. (1984), Service Management: Strategy and Leadership in Service Business, John Wiley \& Sons, Chichester.

Oliver, R.L. (1980), "A cognitive model of the antecedents and consequences of satisfaction decisions", Journal of Marketing Research, Vol. 17 No.September, pp.46-9.

Parasuraman, A., Zeithaml, V.A., Berry, L.L. (1988), "SERVQUAL: A multiple-item scale for measuring customer perceptions of service quality", Journal of Retailing, Vol. 64 No.1, pp.12-40.

Patterson, P.G. (1993), "Expectations and product performance as determinants of satisfaction for high-involvement purchase", Psychology and Marketing, Vol. 10 No.2, pp.449-62. 
Peterson, R.A., Wilson, W.R. (1992), "Measuring customer satisfaction: fact and artifact", Journal of the Academy of Marketing Science, Vol. 20 No.1, pp.61-71.

Richard-Amato, P.A. (1996), Making It Happen: Interaction in the Second Language Classroom, From Theory to Practice, 2nd ed., Longman, White Plains, New York, NY.

Rust, R.T., Zahorik, A.J., Keiningham, T.L. (1994), Return on Quality, Probus Publishing, Chicago, IL.

Schneider, B., Bowen, D.E. (1995), Winning the Service Game, Harvard Business School Press, Boston, MA.

Shamdasani, P.N., Balakrishnan, A.A. (2000), "Determinants of relationship quality and loyalty in personalised services", Asia Pacific Journal of Management, Vol. 17 No.3, pp.399422.

Soutar, G.N., McNeill, M.M., Lim, K. (1994), "Service quality and the overseas student: some Australian experiences", Asia Pacific Journal of Marketing and Logistics, Vol. 6 No.1/2, pp.28-40.

Szymanski, D.M., Henard, D.H. (2001), "Customer satisfaction: a meta-analysis of the empirical evidence", Journal of the Academy of Marketing Science, Vol. 29 No.1, pp.16-35.

Voss, C., Johnston, R., Fitzgerald, L., Sylvestro, R. (1990), "Patterns of measurement of service performance: empirical results", in Teare, R., Moutinho, L., Morgan, N. (Eds),Managing and Marketing Services in the 1990s, Cassell Educational Ltd, London, pp.110-18.

Walker, J. (2000), "Staff perceptions of the service dimension in TESOL", The TESOLANZ Journal, Vol. 8 pp.39-55.

Walker, J. (2001), "Client views of TESOL service: expectations and perceptions", International Journal of Educational Management, Vol. 15 No.4, pp.187-96. 
Client satisfaction with English language centre service: insights from a New Zealand national survey

\author{
Walker, John
}

2003

http://hdl.handle.net/10179/9696

22/04/2023 - Downloaded from MASSEY RESEARCH ONLINE 